\title{
Reconstruction of Post Burn Neck Contracture Using Full Thickness Skin Graft
}

\author{
Dalia M. El Sakka1, Belal A. Al Mobarak², Mohamed Elsayed Mohamed Mohamed2* \\ ${ }^{1}$ Menoufiya University, Al Minufya, Egypt \\ ${ }^{2}$ Plastic Surgery Department, Ahmed Maher Teaching Hospital, Cairo, Egypt \\ Email: *mghabn5777@yahoo.com
}

How to cite this paper: El Sakka, D.M., Al Mobarak, B.A. and Mohamed, M.E.M. (2018) Reconstruction of Post Burn Neck Contracture Using Full Thickness Skin Graft. Modern Plastic Surgery, 8, 21-28. https://doi.org/10.4236/mps.2018.82004

Received: February 13, 2018

Accepted: April 5, 2018

Published: April 8, 2018

Copyright (c) 2018 by authors and Scientific Research Publishing Inc. This work is licensed under the Creative Commons Attribution International License (CC BY 4.0).

http://creativecommons.org/licenses/by/4.0/

(c) (i) Open Access

\begin{abstract}
Background: Neck contracture after burns is a major complication that affects function and cosmesis. The aim of covering the raw area and defects is through using good quality pliable skin. Full thickness skin graft allows a large dimension sheet of good quality skin with low donor-site morbidity. Also it provides similar skin quality to the recipient areas with much less cosmetic difference. Methods: Four men and eight women underwent neck contracture release and reconstruction from December of 2015 to August of 2016. Mean patient age was 29 years (range from 12 to 46 years). Burn scar contracture releases were performed and cervicoplasty was added for optimal neck appearance. Uniformly full thickness skin grafts were applied. Both lateral ends of these grafts (release incisions) were designed with a fishtail shape for sufficient release and to minimize linear scar band formation in the most lateral region of the neck. Results: Full thickness skin grafts as large as $24 \pm 12 \mathrm{~cm}$ (in length) and $10-15 \mathrm{~cm}$ (in width) were used. All grafts were taken without significant complications. Range of neck motion increased, and the cervico-mental angle was regained in all patients. A highly natural neck contour was universally obtained without a secondary debulking procedure. Conclusions: Full thickness skin grafts for treatment of post burn neck contraction give good functional and cosmetic results. They give similar color match and good skin quality, also help in regaining of cervico-mental angle.
\end{abstract}

\section{Keywords}

Neck Contracture, Skin Grafts, Donor Site Morbidity

\section{Introduction}

Neck contracture is both a devastating functional and cosmetic deformity for patients and a challenging problem for the reconstructive surgeons [1]. Severe 
contractures are more common seen in the developing world, a result of both the wide spread of unsafety of fire utilities and the inadequacy of primary and secondary burn care with these victims. When deep burns are allowed to heal spontaneously patients develop severe neck contracture [2].

Various methods have been suggested for releasing post burn neck contractures. When a contracture is limited to a small area, Z-plasties and local skin flaps can successfully resolve these problems [3].

However, when the contractures involve a wide area, it is difficult to reconstruct the anterior neck using conventional methods, such as split thickness skin grafting or local flaps, because split thickness skin grafting often results in postoperative re-contracture, and the amount of uninvolved skin available for use as a local flap is insufficient [4].

Full thickness skin grafts have several advantages, as they provide sufficient tissue with excellent function, and provide a good neck contour without significant donor site morbidity [5].

The ideal material for coverage of defects created after neck contracture release would be a thin, supple, large, well-vascularized healthy tissue [6].

Given the increasing preference for full thickness skin graft, a wide spectrum of reconstruction cases, resurfacing after contracture release has become another indication for use of full thickness skin graft. Thus, several full thickness skin graft donor sites have been selected for the reconstruction of burn scar contractures in various regions of the body, including the neck [7].

The lower abdominal skin can provide generous skin territory dimensions without causing significant donor-site morbidity. The back is the 2nd preferred donor site [7].

In this article, we present 12 cases of severe burn neck contractures reconstructed with good results using full thickness skin graft and cervicoplasty.

\section{Patients and Methods}

From December of 2015 to August of 2016, 12 patients with severe post burn neck contracture were treated using full thickness skin graft with cervicoplasty. The patient group was composed of four men and eight women, with a mean age of 29 years (range, 12 to 46 years). Eleven patients had flame burns and only one patient had scald burn injury (Table 1 ).

Patients who had burns affecting the suggested donor sites were excluded from the study. Also patients who had not any excess of skin in the chosen sites for donor sites and patients who refused to harvest grafts from these specific sites were also excluded from the study.

The patients complained of significant tightness, limitations of motion in the anterior cervical region, and an unnatural appearance. Preoperatively, cervical range of motion was measured in the six primary directions: flexion, extension, right and left rotation, and right and left lateral flexion. In addition, the cervico-mental angle was recorded. Lower abdomen or back regions which were free of burn injuries, were selected as a donor site for reconstruction in all cases. 
Table 1. Patients sheet showing Demographic data of the 12 patients and characteristics of the skin grafting.

\begin{tabular}{|c|c|c|c|c|c|c|}
\hline \multirow{2}{*}{ No } & \multirow{2}{*}{ Age } & \multirow{2}{*}{ Sex } & \multirow{2}{*}{ Type of deformity } & \multirow{2}{*}{ Donor sites } & \multicolumn{2}{|c|}{ Complications } \\
\hline & & & & & Recipient site & Donor site \\
\hline 1 & 33 & $\mathrm{~F}$ & Neck contracture & Abdomen & $\begin{array}{c}\text { Superficial } \\
\text { desquamation }\end{array}$ & ----- \\
\hline 2 & 30 & M & $\begin{array}{c}\text { Neck contracture } \\
\text { Lower lip ectropion. }\end{array}$ & Abdomen & $\begin{array}{c}\text { Superficial } \\
\text { desquamation }\end{array}$ & ----- \\
\hline 3 & 20 & $\mathrm{~F}$ & Neck contracture. & Back (transverse) & ----- & ----- \\
\hline 4 & 17 & $\mathrm{~F}$ & $\begin{array}{c}\text { Neck contracture } \\
\text { Lower lip ectropion }\end{array}$ & Back (transverse) & $\begin{array}{c}\text { Superficial } \\
\text { desquamation }\end{array}$ & $\begin{array}{l}\text { Partial wound } \\
\text { disruption }\end{array}$ \\
\hline 5 & 40 & $\mathrm{~F}$ & $\begin{array}{c}\text { Neck contracture } \\
\text { Deformity of the chin }\end{array}$ & Back (transverse) & ------ & ----- \\
\hline 6 & 23 & M & $\begin{array}{c}\text { Neck contracture } \\
\text { Deformed lower lip. }\end{array}$ & Abdomen & & $\begin{array}{l}\text { Hypertrophy of } \\
\text { the grafted donor }\end{array}$ \\
\hline 7 & 22 & $\mathrm{~F}$ & $\begin{array}{c}\text { Neck contracture } \\
\text { Lower lip ectropion. }\end{array}$ & Back (transverse) & ----- & ------ \\
\hline 8 & 34 & $\mathrm{~F}$ & Neck contracture. & Back (transverse) & ----- & ----- \\
\hline 9 & 41 & $\mathrm{~F}$ & Neck contracture & Abdomen & $\begin{array}{c}\text { Superficial } \\
\text { desquamation }\end{array}$ & $\begin{array}{l}\text { Partial wound } \\
\text { disruption }\end{array}$ \\
\hline 10 & 28 & $\mathrm{~F}$ & Neck contracture & Abdomen & $\begin{array}{c}\text { Superficial } \\
\text { desquamation }\end{array}$ & ------- \\
\hline 11 & 23 & M & Neck contracture & Abdomen & ------- & -------- \\
\hline 12 & 34 & M & Neck contracture & Abdomen & ------- & ----- \\
\hline
\end{tabular}

\section{Surgical Technique}

Contracture release was performed with the patient placed supine, neck and shoulder were in hyperextension. Horizontal contracted scar excision, several centimeters wide, was performed at a level just beneath the deep fascia and all fibrous tissues were removed to release the contracture completely. Both lateral ends of releasing skin incisions were fish-tail reshaped for release of the lateral cervical contracture sufficiently and to prevent the development of postoperative linear scar contracture. After meticulous hemostasis with bipolar cauterization and irrigation, they were prepared for grafts. The recipient site determined the size of the harvested full thickness skin graft.

With classic abdominoplasty or mini abdominoplasty incisions, initially full thickness skin was excised and then the donor sites were closed primarily. Back was the $2^{\text {nd }}$ preferred donor site if the lower abdominal skin not Sufficient due to burn scar or in thin patients and also the donor site was closed primarily either horizontally or longitudinally (Figures 1 (a)-(f)).

The full thickness skin (FTS) was defatted meticulously up to subdermal area, making it a thin FTS

It was possible to harvest Full thickness skin grafts as large as $24 \pm 12 \mathrm{~cm}$ (in length) and $10-15 \mathrm{~cm}$ (in width), as one or two sheets. This allowed the grafts to completely cover the whole raw area extending from the lower border of the 


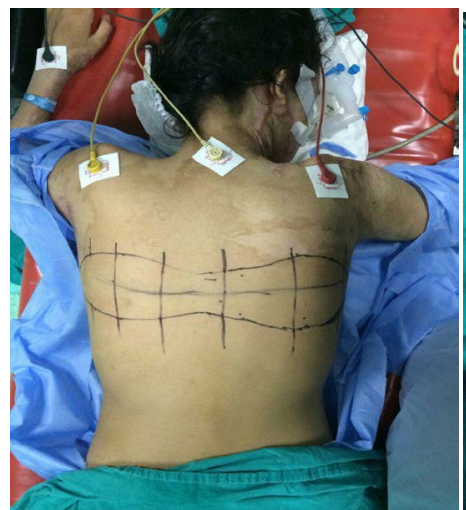

(a)

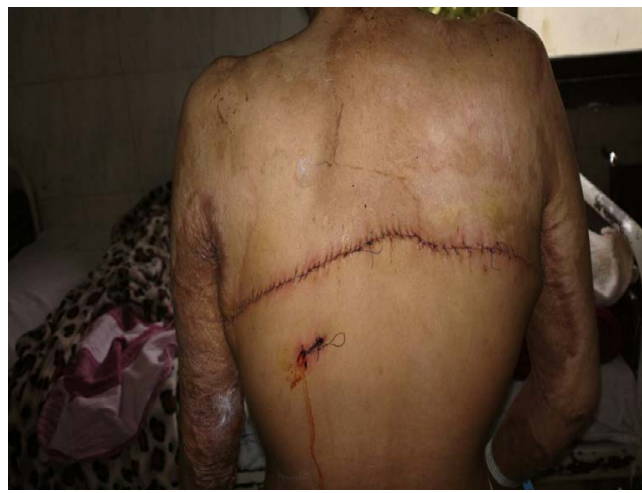

(d)

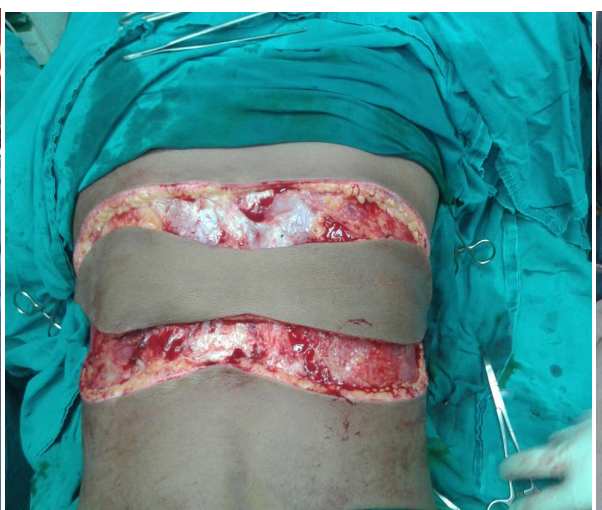

(b)

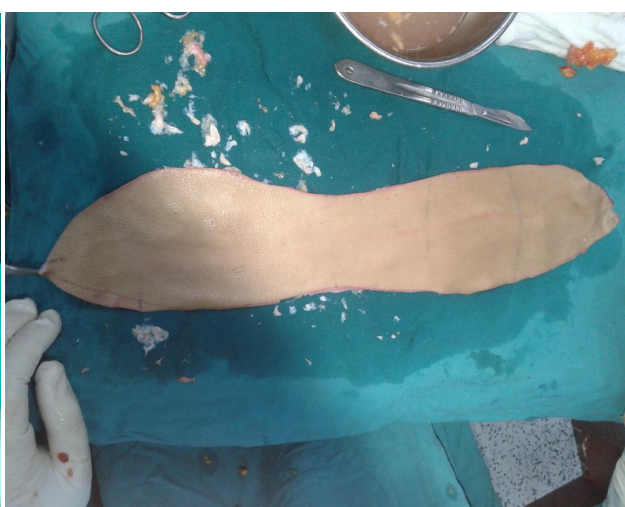

(c)

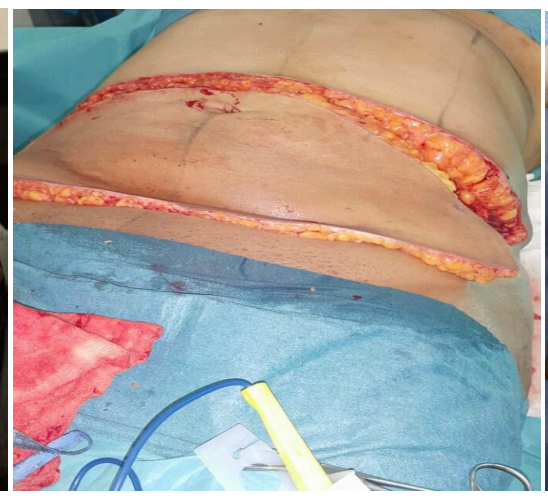

(e)

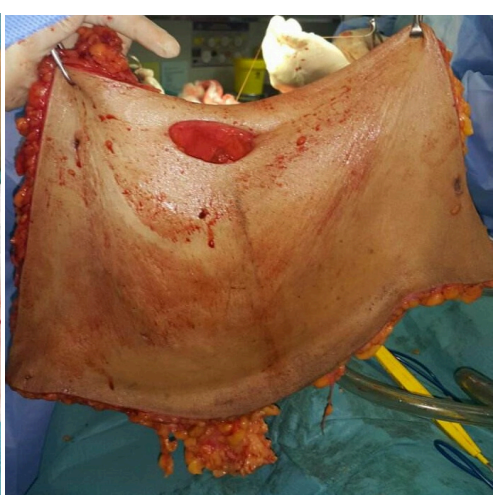

(f)

Figure 1. Full thickness skin graft design and harvesting. (a) Design of Full thickness skin graft FTSG from back; (b) Intra-operative harvesting of FTSG; (c) FTSG harvested from the back; (d) Donor site in the back was closed directly; (e) Abdominoplasty with the whole skin sheet in place; (f) Skin taken from the abdomen to be used as a full thickness skin graft.

clavicle and up to the lower lip after full extension of the neck and good definition of cervico-mental angle. Laterally it can reach just behind sternomastoid muscle.

The grafts were sutured to underlying bed and fixed with tie over bolster dressing.

All patients were done in both hospitals free of charges and follow up of the patients continued for 6 months post-operative.

First and second dressings were done in the word. All patients were discharged after the second dressing. Patients were followed up in the out patient clinic once weekly for one month, then once monthly for the rest of 6 months.

Local creams and ointments were used to enhance healing. Cervical collars were applied for 6 months.

\section{Results}

In all cases, moderately good skin color and texture match was achieved. The functional and aesthetic result was considerably improved by the use of full thickness skin graft either from the abdominal skin or from the back (Figure 2, Figure 3). Donor site morbidity was not observed while abdominoplasty helped to improve the negative body image. 


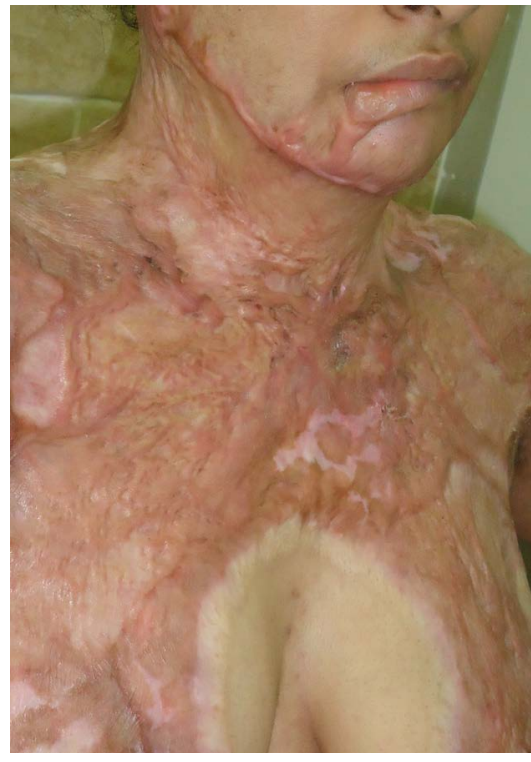

(a)

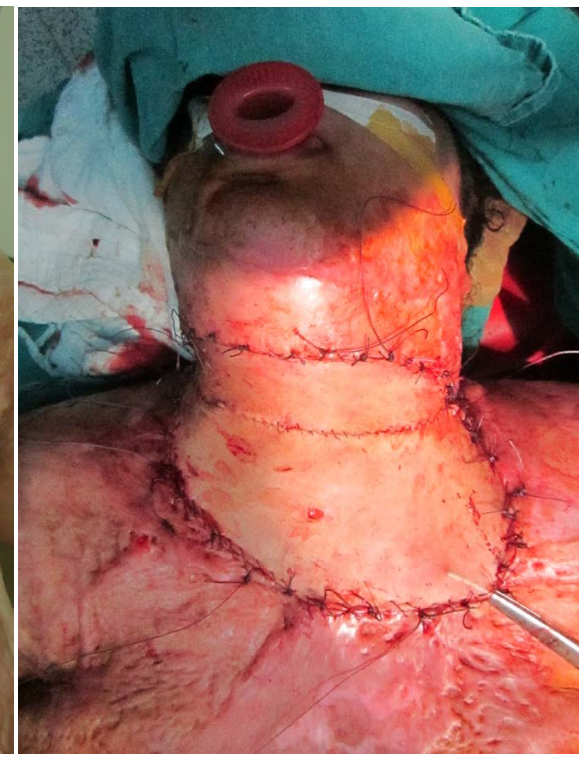

(b)

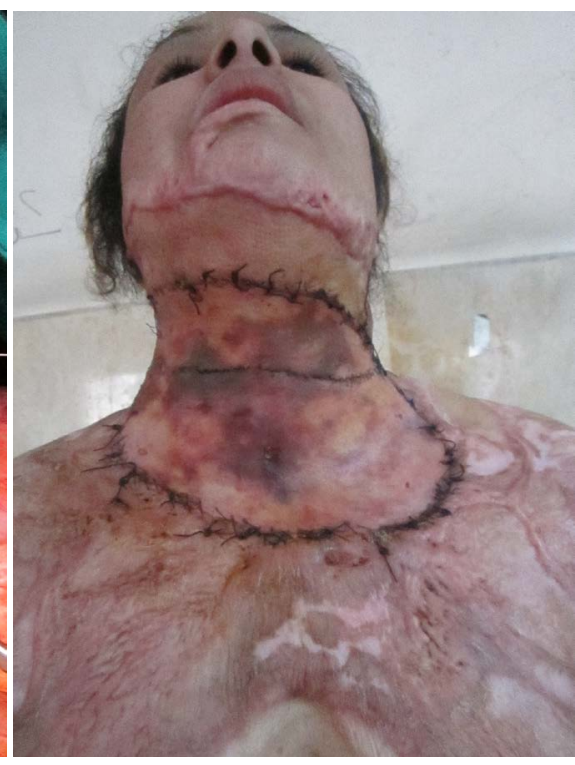

(c)

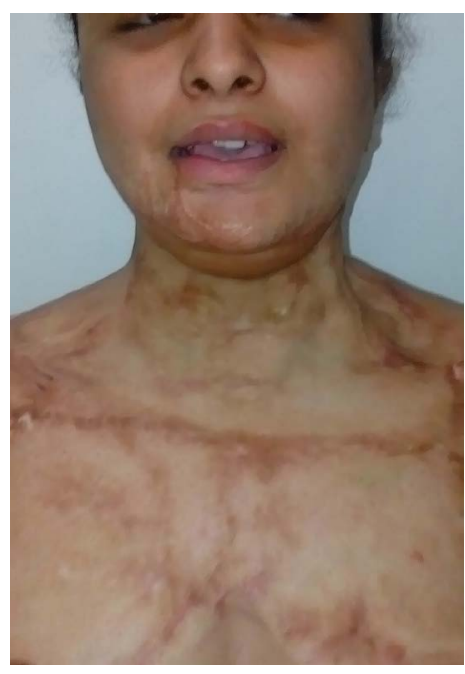

(d)

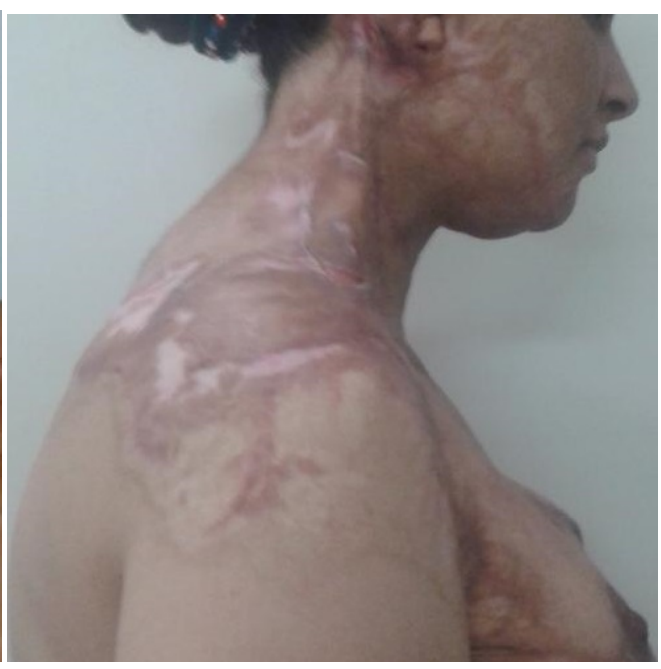

(e)

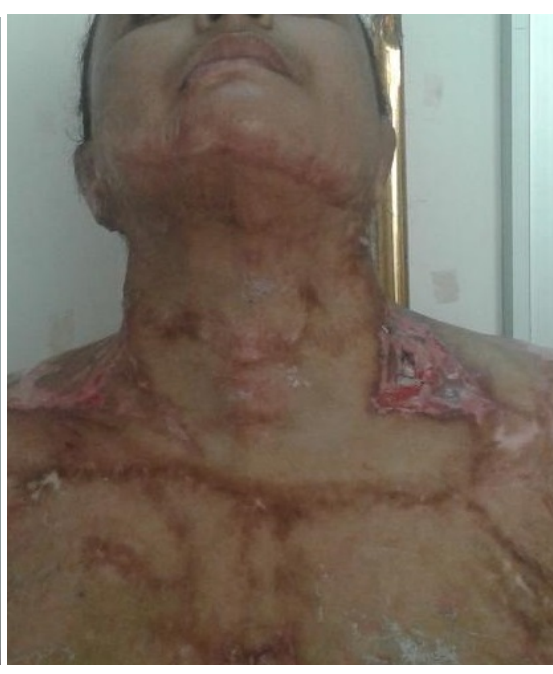

(f)

Figure 2. A 34 years old woman with post burn neck contracture. Neck extension improved considerably after operation; (a) Preoperative oblique lateral view with contracted neck and ugly keloid scarring; (b) Intra-operative view after application of FTSG; (c) Five days post-operative after application of the graft; (d) Late post-operative anterior view; (e) Late post-operative lateral view with preserved cervico-mental angle; (f) Late post-operative anterior view with maximum neck extension.

\section{Discussion}

The neck is a region with multidirectional activities, and postoperative scar contractures tend to form there easily. In addition, the neck is a sensitive region, not only from the functional but also from the aesthetic point of view, and in burn patients especially; disfigurements such as ectropion of the lips are liable to occur. Many methods have been applied for neck reconstruction; each has its own advantages and disadvantages [8].

The primary aim of a plastic surgeon is to prevent burn scar deformity by rapid wound coverage, minimizing burn scar and assiduous attention to post-operative splinting and compression therapy [9]. 


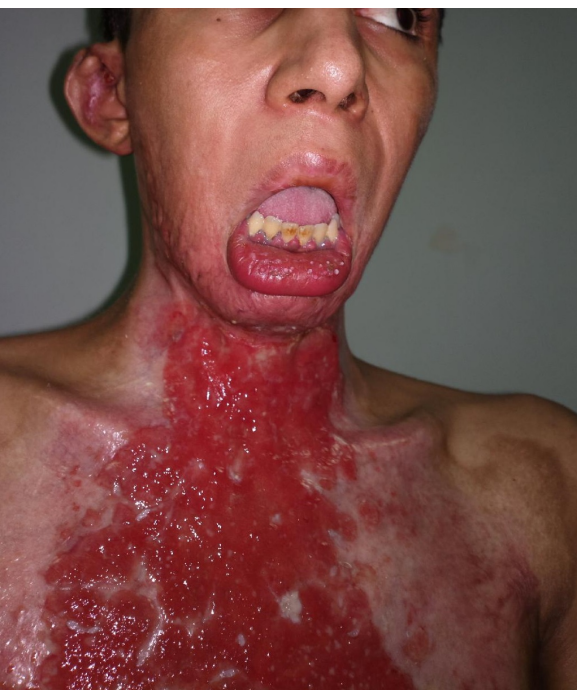

(a)

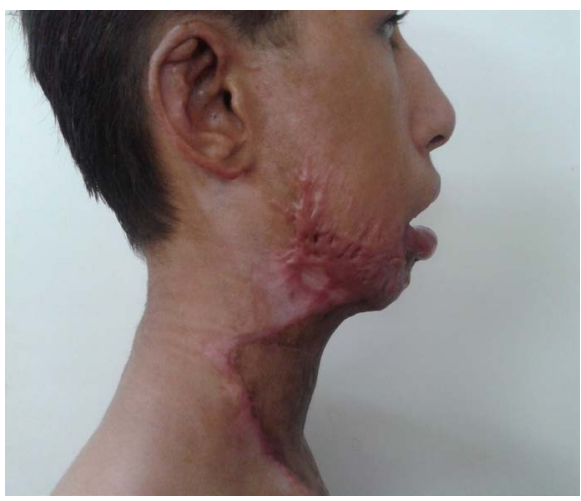

(c)

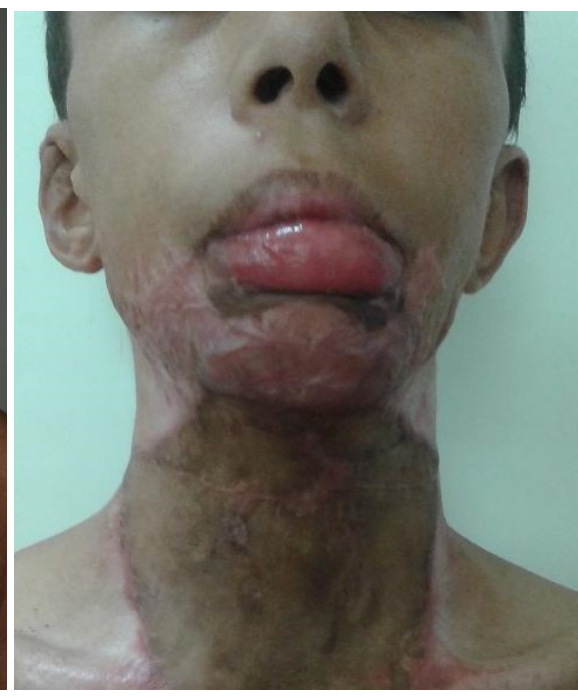

(b)

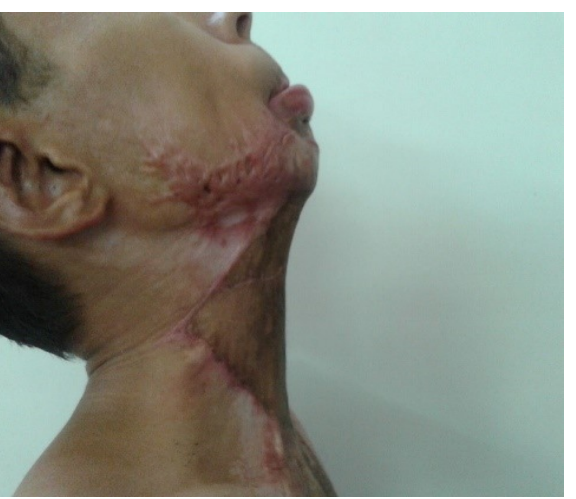

(d)

Figure 3. A 24 years old male with burn raw area in neck following flame burn. (a) Pre-operative raw area of the neck and contracture, also lower lip ectropion; (b) Post-operative anterior view with FTSG applied; (c) Post-operative lateral view.

Reconstruction of deformities in a burn patient is often a complex multi-stage procedure requiring repeated surgeries. The approach presented here advocates a step wise prioritized approach aiming at both maximum function as well as aesthetic improvement. Post-burn contractures may require surgical release and for the split-thickness or full-thickness skin-graft coverage, local flaps or free flaps may be considered [10].

Burn contractures of neck represent a continuing problem for plastic surgeons. This was especially true in those patients who had previously suffered from burns to entire anterior neck and shoulder. These patients needed grafts because the adjacent skin could not be used as local flaps following tissue expansion. One advantage of skin grafts is that non-bulky skin from a previously uninjured area of the body is used instead of scarred and compromised adjacent skin. Full-thickness skin grafts resemble more closely to normal skin in texture, color, and resilience than split-thickness grafts. However, the take of full-thickness skin grafts is less than split thickness skin graft, and also suffer from the drawback of 
limited availability [11].

Full-thickness grafts also contract much less as there is an inverse relationship between thickness and graft contracture [12]. Iregbulem reported excellent "take "with no graft loss in a review of full-thickness skin grafts used in post burn contracture releases in 136 consecutive cases [13]. We were not confronted with any graft loss.

Mini abdominoplasty or traditional abdominoplasty may be combined with burn reconstruction to provide a good skin quality in a single operation. The excess skin from the site of cosmetic procedure could be used for resurfacing medium and large burn areas. In the use of skin grafts for post burn contracture release is simple, reliable, and safe. They are particularly useful when we don't have other options such as local flaps or highly demanding unavailable other reconstructive methods like microvascular free flaps.

Their main disadvantage is tendency to form contractures which necessitates further release; however that is much less when using full thickness skin grafts. The excess skin from the site of an aesthetic procedure could be used for this problem. We believe that FTSG harvested from abdominoplasty site is a good option after removal of burn scars of face and neck, without donor site morbidity and improved patients body contour.

\section{Conclusion}

Full thickness skin grafts for treatment of post burn neck contraction give good functional and cosmetic results. They give similar color match and good skin quality, also help in regaining of cervico-mental angle.

\section{References}

[1] Wilson, I.F., Lokeh, A., Schubert, W. and Benjamin, C.I. (2000) Reconstruction of Neck and Axillary Burn Contractures. Plastic and Reconstructive Surgery, 105, 27-33. https://doi.org/10.1097/00006534-200001000-00005

[2] Antia, N.H. (1985) Organization of Plastic in Developing Countries. British Journal of Plastic Surgery, 38, 24-29. https://doi.org/10.1016/0007-1226(85)90082-7

[3] Ohkubo, E., Kobayashi, S., Sekiguchi, J., et al. (1990) Restoration of the Anterior Neck Surface in the Burned Patient by Free Groin Flap. Plastic \& Reconstructive Surgery, 84, 276-284.

[4] Angrigiani, C. (1994) Aesthetic Microsurgical Reconstruction of Anterior Neck Burn Deformities. Plastic \& Reconstructive Surgery, 93, 507-518. https://doi.org/10.1097/00006534-199493030-00009

[5] Tseng, W.S., Cheng, M.H., Tung, T.C., et al. (1999) Microsurgical Combined Scapular/Parascapular Flap for Reconstruction of Severe Neck Contracture: Case Report and Literature Review. The Journal of Trauma: Injury, Infection, and Critical Care, 47, 1142. https://doi.org/10.1097/00005373-199912000-00029

[6] Ninkovic, M., Moser-Rumer, A., Ninkovic, M., et al. (2004) Anterior Neck Reconstruction with Pre-Expanded Free Groin and Scapular Flaps. Plastic and Reconstructive Surgery, 113, 61-68. https://doi.org/10.1097/01.PRS.0000090726.45594.6B

[7] Engrav, L.H. and Donelan, M.B. (2006) Acute Care and Reconstruction of Facial 
Burns. In: Mathes, S. and Hentz, V., Eds., Textbook of Plastic Surgery, 2nd Edition, Elsevier and Saunders, Philadelphia, Vol. 3, 45-77.

[8] Hyakusoku, H. and Gao, J.H. (1994) The "Super-Thin" Flap. British Journal of Plastic Surgery, 47, 457-464. https://doi.org/10.1016/0007-1226(94)90027-2

[9] Ogawa, R. and Hyakusoku, H. (2003) Color Doppler Ultrasonography in the Planning of Microvascular Augmented Super-Thin (SVN: Subdermal Vascular Network) Flaps. Plastic and Reconstructive Surgery, 112, 822-828. https://doi.org/10.1097/01.PRS.0000070176.30065.65

[10] Mc Gregor, I.A., Ed. (1989) Fundamental Techniques of Plastic Surgery and Their Surgical Applications. 8th Edition, Churchill Livingstone, Edinburgh, 39-63.

[11] Grabb, W.C. (1979) Basic Techniques of Plastic Surgery. In: Grabb, W.C. and Smith, J.S., Eds., Plastic Surgery, 3rd Edition, Little Brown, Boston, 3-74.

[12] Jankauskas, S., Cohen, I.K. and Graff, W.C. (1991) Basic Techniques of Plastic Surgery. In: Smith, J.W. and Aston, S.J., Eds., Grabb and Smith's Plastic Surgery, 4th Edition, Little Brown, Boston, 3-90.

[13] Iregbulem, L.M. (1980) Post Burn Volar Digital Contractures in Nigerians. Hand, 12, 54-61. https://doi.org/10.1016/S0072-968X(80)80030-1 